\title{
A hemicyanine and cucurbit[n]uril inclusion complex: competitive guest binding of cucurbit[7]uril and cucurbit[8]uril
}

Weitao Xu, ${ }^{a}$ Jinglan Kan, ${ }^{\mathrm{b}}$ Carl Redshaw, ${ }^{\mathrm{c*}}$ Bing Bian, ${ }^{\mathrm{d}}$ Ying Fan, ${ }^{\mathrm{a}}$ Zhu Tao, ${ }^{\mathrm{a}}$ and $\mathrm{Xin} \mathrm{Xiao}^{\mathrm{a}^{*}}$

a. Key Laboratory of Macrocyclic and Supramolecular Chemistry of Guizhou Province, Guizhou University, Guiyang 550025, China

b. College of Chemistry, Chemical Engineering and Materials Science, Collaborative Innovation Center of Functionalized Probes for Chemical Imaging in Universities of Shandong, Key Laboratory of Molecular and Nano Probes, Ministry of Education, Shandong Normal University, Jinan 250014, China

c. Department of Chemistry \& Biochemistry, University of Hull, Hull HU6 7RX, U.K.

d. College of Chemistry and Environmental Engineering, Shandong University of Science and Technology, Qingdao 266590, China.

*Corresponding authors. Tel./fax: +86 15519089928 (X.X.); +44 1482465219 (C.R.)

E-mail addresses: gyhxxiaoxin@163.com (X. Xiao); c.redshaw@hull.ac.uk (C. Redshaw). 


\title{
A hemicyanine and cucurbit[n]uril inclusion complex: competitive guest binding of cucurbit[7]uril and cucurbit[8]uril
}

\author{
The interaction between the hemicyanine indole derivative $\mathrm{H}$ and the \\ cucubit[n]urils Q[7] and Q[8] has been studied using ${ }^{1} \mathrm{H}$ NMR and UV \\ spectroscopy as well as by fluorescence experiments. Competitive studies on the \\ inclusion of $\mathrm{H}$ by Q[7] and Q[8] have also been conducted, and reveal that on \\ changing the size of the $\mathrm{Q}[n]$ cavity, the binding behaviour can be very different.
}

Keywords: Hemicyanine, Cucubit[n]urils, Competitive binding, Host-guest

\section{Introduction}

Cyanines have long been recognised as useful dye materials, and have found widespread use in the healthcare industry for example in immunoassays (1-7). They have also been employed in the production of CDs and DVDs, however there are issues with chemical stability which render the discs unreadable over time. Although there have been some advances in stability via the use of stabilizes/additives to afford socalled 'metal-stabilized cyanine' or 'super cyanine', there is still room for improvement given the sensitivity of these systems to UV-rays. During our host-guest inclusion studies using cucubit[n]urils, $\mathrm{Q}[n] \mathrm{s}$, and small molecules (8-13), we and others (14-17) have noted that the inclusion complex is often more stable than its parent parts. Furthermore, encapsulation of dyes by $\mathrm{Q}[n]$ s can lead to fluorescent enhancement (18). With this in mind, we have investigated herein the inclusion complex formed between the $Q[n]$ s, where $n=7$ or 8 , and the hemicyanine $H$ - see scheme 1 . As part of this work, we have also conducted competition studies on the use of Q[7] and Q[8] towards H.

The interaction of Q[7] with the two cyanine dyes pseudoisocyanine (A) and pinacyanol (B) (see scheme 2) has previously been studied in the presence of the 
polystyrenesulfonate as J- and $\mathrm{H}$-aggregate promoter (19). The host-guest chemistry of the same cucubituril was also examined with the cyanine-type dyes $C$ to $G$ (see scheme 3), and fluorescent lifetimes were found to be extended (20). We also note that some dyes of this type have been used in a number of applications where DNA damage has been induced (21-24).

\section{Experimental section}

\subsection{Materials and apparatus}

The hosts Q[7] and Q[8] were prepared according to the literature methods (25-27). 2,3,3-Trimethylindolenine was obtained from Aldrich and was used without further purification. All other reagents were of analytical grade and were used as received. Double-distilled water was used for all experiments.

Preparation of H/Q[7]: The required amounts of Q[7] and $\mathrm{H}$ were respectively weighed according to the ratio of $\mathrm{N}_{\mathrm{Q}[7]}: \mathrm{N}_{\mathrm{H}}=1: 1$, and then dissolved in distilled water and stirred for $30 \mathrm{~min}$. The solvent was then evaporated to afford the 1:1 inclusion compound H/Q[7]. The same procedure was employed for the H/Q[8] system.

\section{Synthesis of $\mathrm{H}$}

\section{Synthesis of 1}

2,3,3-Trimethylindolenine (796.15 mg, $5 \mathrm{mmol}$ ) and iodomethane (4258.80 mg, 30 mmol) were dissolved in acetonitrile $(40 \mathrm{~mL})$. The solution was stirred under an inert nitrogen atmosphere at reflux for $12 \mathrm{~h}$. On cooling, the resulting solution was filtered and the brown precipitate was washed with diethyl ether and then dried in vacuum to afford 1 (1280.00 mg, 85\%). ${ }^{1} \mathrm{H}$ NMR $\left(\mathrm{DMSO}_{\mathrm{d} 6}, 400 \mathrm{MHz}\right) \delta 7.90$ (d, J = 5.9, $2.9 \mathrm{~Hz}$, 1H), 7.82 (t, 1H), $7.64-7.60$ (m, 2H), 3.96 (s, 3H), 2.75 (s, 3H), 1.52 (s, 6H). 


\section{Synthesis of $\mathrm{H}$}

The dye $\mathrm{H}$ was synthesized according to the reported procedure (28).

1 (301.17 mg, $1.0 \mathrm{mmol}$ ) and 4-dimethylaminobenzaldehyde (179.028 mg, $1.2 \mathrm{mmol}$ ) were dissolved in ethyl alcohol (40 mL). The solution was stirred at reflux under an inert nitrogen atmosphere for $12 \mathrm{~h}$. On cooling, the resulting solution was filtered and the kermesinus-like precipitate was washed with diethyl ether and then dried in vacuum to give $\mathrm{H}$ (376.14 mg, 87\%). ${ }^{1} \mathrm{H}$ NMR ( $\mathrm{D}_{2} \mathrm{O}, 400 \mathrm{MHz}$, ) $\delta 8.04(\mathrm{~d}, \mathrm{~J}=15.7 \mathrm{~Hz}, 1 \mathrm{H})$, 7.66 (d, J = 9.0 Hz, 2H), 7.46 (d, J = 7.2 Hz, 1H), $7.39-7.28$ (m, 3H), 6.91 (d, J = 15.6 Hz, 1H), 6.70 (d, J = 9.0 Hz, 2H), 3.69 (s, 3H), 2.95 (s, 6H), 1.57 (s, 6H).

\section{2. ${ }^{1} \mathrm{H}$ NMR spectroscopy}

To study the host-guest complexation of Q[7]/Q[8] and $\mathrm{H}$, all the ${ }^{1} \mathrm{H}$ NMR spectra, including those for the titration experiments, were recorded at $298.15 \mathrm{~K}$ on a JEOL JNM-ECZ400S $400 \mathrm{MHz}$ NMR spectrometer (JEOL) in $\mathrm{D}_{2} \mathrm{O} . \mathrm{D}_{2} \mathrm{O}$ was used as a fieldfrequency lock, and the observed chemical shifts are reported in parts per million (ppm). The concentration of Q[7]/Q[8] employed in the NMR experiments was $5.0 \times 10^{-4}$ $\mathrm{mol} / \mathrm{L}$.

\subsection{UV-Vis absorption and fluorescence emission spectra}

UV-vis absorption spectra of the host-guest complexes were recorded using an Agilent 8453 spectrophotometer at room temperature. Fluorescence emission spectra were recorded on a VARIAN Cary Eclipse spectrofluorometer (Varian, Inc., Palo Alto, CA, USA). The Fluorescence spectra were obtained by excitation at $540 \mathrm{~nm}$ with $10 \mathrm{~nm}$ emissions and excitation bandwidths. The aqueous solution of $\mathrm{H}$ was prepared with a concentration of $1.00 \times 10^{-4} \mathrm{~mol} / \mathrm{L}$. An aqueous solution of Q[7]/Q[8] was prepared with a concentration of $1.00 \times 10^{-4} \mathrm{~mol} / \mathrm{L}$ for absorption spectra 
determination. The UV-vis absorption experiments were performed as follows: $1 \mathrm{~mL}$ of a $1.00 \times 10^{-4} \mathrm{~mol} / \mathrm{L}$ stock solution of $\mathrm{H}$ and various amounts of an aqueous $1.0 \times 10^{-4}$ $\mathrm{mol} / \mathrm{L} \mathrm{Q}$ [7] solution were transferred into a $10 \mathrm{~mL}$ volumetric flask, and then the volumetric flask was filled to the final volume with distilled water. Samples of these solutions were combined to give solutions with an $\mathrm{H}: \mathrm{Q}[7] / \mathrm{Q}[8]$ ratio of $0,0.2,0.4$, 0.6...... and 3.0. The formation constants of the H@Q[7]/Q[8] complexes (K) (1:1) were calculated according to curve fitting method. The Jobs plot method was used to determine the inclusion ratio of the substance, $\mathrm{N}_{\mathrm{Q}[7]}: \mathrm{N}_{(\mathrm{Q}[7]+\mathrm{H})}=0,0.1,0.2,0.3, \ldots, 1.0$.

\subsection{MALDI-TOF Mass spectrometry}

MALDI-TOF mass spectrometry was recorded on a Bruker BIFLEX III ultrahigh resolution Fourier transform ion cyclotron resonance (FT-ICR) mass spectrometer with a-cyano-4-hydroxycinnamic acid as matrix.

\section{Result and discussion}

\subsection{Inclusion complex of $H$ and $Q[7]$}

The binding interactions between the guest $\mathrm{H}$ and Q[7] can be conveniently monitored using ${ }^{1} \mathrm{H}$ NMR spectroscopic data recorded in neutral $\mathrm{D}_{2} \mathrm{O}$ solution. Figure 1 (and table S1) shows the changes observed in the ${ }^{1} \mathrm{H}$ NMR spectrum of $\mathrm{H}$ as progressively larger amounts of Q[7] are added to the solution. Clear up-field shifts of the signals of the protons g to k were observed as Q[7] was added, whilst the protons at the end of the molecule bearing the quaternary nitrogen experienced little change. This indicates that the 4-NMe 2 -phenyl motif and the ethylene linker were accommodated within the cavity of Q[7] and the quaternary ammonium part was out the portal (see cartoon, top right figure 1). The addition of a second equivalent of Q[7] had little effect on the 1:1 inclusion complex. 
To further understand the binding of the guest $\mathrm{H}$ to Q[7], we also employed UVvis spectroscopy (figure 2). The UV-vis spectra were obtained using aqueous solutions containing a fixed concentration of guest $\mathrm{H}\left(1.0 \times 10^{-5} \mathrm{~mol} \cdot \mathrm{L}^{-1}\right)$ and variable concentrations of Q[7]. The dye $\mathbf{H}$ has an absorption maximum centered at $559 \mathrm{~nm}$. On gradually increasing the Q[7] concentration in the $\mathrm{H}$ solution, the absorption band of the guest exhibits a progressively higher absorbance due to the formation of the host-guest complex Q[7]@H. Similar experiments were performed using fluorescence spectroscopy, and as shown in figure 2C, the fluorescence emission of $\mathbf{H}$ occurs at 600 $\mathrm{nm}$ with an excitation wavelength at $540 \mathrm{~nm}$ in aqueous solution. On gradual addition of $\mathrm{Q}[7]$ to a solution of the guest $\mathrm{H}$, the emission spectra of $\mathrm{H}$ progressively decreased in intensity as the $\mathrm{n}_{(\mathrm{Q}[7])} / \mathrm{n}_{(\mathrm{H})}$ ratio increased. The UV and fluorescence data for the molar ratio of the host $\mathrm{Q}[7]$ to the guest $\mathrm{H}$ can be fitted to a 1:1 binding model.

\subsection{Inclusion complex of $\mathrm{H}$ and Q[8]}

A similar investigation of the interaction of $\mathrm{H}$ and $\mathrm{Q}[8]$ by ${ }^{1} \mathrm{H}$ NMR spectroscopy (see Figure 3 and Table S2), again revealed chemical shift changes consistent with encapsulation of the 4-NMe 2 -phenyl motif and the ethylene linker, whilst the quaternary ammonium part was out the portal (see cartoon right side figure 3). Interestingly, on addition of a second equivalent of Q[8], the data is consistent with a situation where only the quaternary ammonium part is included, while the 4-NMe phenyl motif lies outside the portal but is adjacent the second Q[8] molecule (see cartoon bottom right figure 3).

Upon addition of Q[8], the complexation of $\mathrm{H}$ afforded a decrease from 0.68 to 0.59 in the absorption (see figure 4 A, B) until a 1:1 host-guest ratio was achieved. On further addition of Q[8], the UV absorption band of the guest exhibited progressively higher absorbance until the $\mathrm{n}_{(\mathrm{Q}[8])} / \mathrm{n}_{(\mathrm{H})}$ was 2:1. These observations were consistent with 
the initial formation of a 1:1 host-guest complex, and then the subsequent formation of a 2:1 host-guest inclusion complexes as the Q[8] concentration was increased. Further support for this comes from the fluorescence spectroscopic results, which are shown in figure 4 C, D. When increasing amounts of host Q[8] were added to $\mathrm{H}$, a decrease in the emission intensity at the maximum emission wavelength $(596 \mathrm{~nm})$ was observed until a 1:1 host-guest ratio was achieved. On further addition of Q[8], the same phenomena were observed to those observed in the UV spectra. These results are consistent with the observed ${ }^{1} \mathrm{H}$ NMR spectra (figure 3). The MALDI-TOF mass spectrometry experiments provided further evidence for the formation of a 1:1 stoichiometry for the host - guest inclusion complexes of Q[7]/ Q[8] and guest $\mathrm{H}$. In their MALDI-TOF MS spectra (figure 5), major signals were observed at $\mathrm{m} / \mathrm{z}=1468.839$ and $\mathrm{m} / \mathrm{z}=1634.516$, which

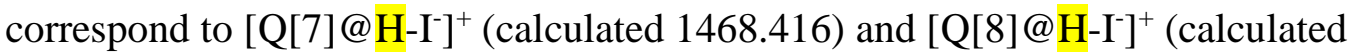
1634.556).

\subsection{Competition experiments of $H$ with $Q[7]$ and $Q[8]$}

We have also carried out competition studies on this system to ascertain whether there is a preference for inclusion by Q[7] or Q[8]. The ${ }^{1} \mathrm{H}$ NMR spectra shown in Figure 6 (and table S3) represent the system where Q[7] is first added, and we have discussed the results above. Once the molar ratio of Q[7] and $\mathrm{H}$ was about 1.0 (figure 6B), subsequently Q[8] (0.87 equiv. of Q[8], figure 6C; 1.80 equiv. of Q[8] figure 6D) was added. A slight down-field shift of the signals of the protons of the 4-NMe 2 -phenyl motif and an obvious up-field shift of the signals of the protons of the ethylene linker and the quaternary ammonium part was observed as Q[8] was added compared to the situation when the molar ratio of Q[7] and $\mathrm{H}$ at about 1.0. The specific shifts are as follows: the resonances of protons $\mathrm{Hh}, \mathrm{He}, \mathrm{Hg}, \mathrm{Hf}$ and $\mathrm{Ha}$ of $\mathrm{H}$ exhibited an up-field shift of $0.02 \mathrm{ppm}$ (from $7.87 \mathrm{ppm}$ to $7.04 \mathrm{ppm}$ ), $0.47 \mathrm{ppm}$ (from $7.51 \mathrm{ppm}$ to $5.91 \mathrm{ppm}$ ), 
$0.45 \mathrm{ppm}$ (from $6.94 \mathrm{ppm}$ to $6.49 \mathrm{ppm}$ ), $0.87 \mathrm{ppm}$ (from $3.96 \mathrm{ppm}$ to $3.09 \mathrm{ppm}$ ), and $0.83 \mathrm{ppm}$ (from $1.80 \mathrm{ppm}$ to $0.97 \mathrm{ppm}$ ), and the resonances of protons Hd-Hc became two groups of peaks (at 7.16, $7.04 \mathrm{ppm}$ ) when Q[8] was added. This indicates that the quaternary ammonium part and the ethylene linker were accommodated within the cavity of the Q[8] and that the 4-NMe 2 -phenyl motif was external, ie out of the portal (see cartoon), whilst the Q[7] no longer includes any of $\mathrm{H}$.

To further investigate the competition between $\mathrm{H}$ with Q[7] and Q[8], we examined the bonding behaviour of the host - guest inclusion complexes via spectroscopic methods (absorption and fluorescence spectroscopy). As shown in figure 7, when the host-guest ratio $\mathrm{n}(\mathrm{Q}[7]) / \mathrm{n}(\mathrm{H})$ was fixed at 1:1, and $\mathrm{Q}[8]$ was then added to this solution, the UV absorption and fluorescence spectra underwent marked changes. This is consistent with the differing binding behaviour of $\mathrm{Q}[8]$ towards $\mathrm{H}$ compared to that of Q[7].

\section{Conclusions}

In conclusion, we have investigated the host guest chemistry between the hemicyanine indole derivatives $\mathrm{H}$ and the cucubit[n]urils Q[7] and Q[8]. Results indicate that there is a preference for inclusion of the 4-NMe2-phenyl motif and the ethylene linker. However, if the studies are conducted in the presence of a second equivalent of $\mathrm{Q}[n]$, then, when $\mathrm{n}$ $=8$, the situation is reversed and there is a preference for inclusion of the quaternary ammonium motif. This contrasts with the behavior observed for Q[7] (see figure 1), where use of excess Q[7] has no effect on the 1:1 inclusion complex.

\section{ACKNOWLEDGMENT}

The Natural Science Foundation of China (21861011), the Major Program for Creative Research Groups of Guizhou Provincial Education Department (2017-028), the 
Innovation Program for High-level Talents of Guizhou Province (No. 2016-5657) and the Science and Technology Fund of Guizhou Province (No. 2016-1030, 2018-5781) are gratefully acknowledged for financial support. CR thanks the EPSRC for a travel grant (EP/L012804/1).

Corresponding Authors

*E-mail: gyhxxiaoxin@163.com (Xiao X.); c.redshaw@hull.ac.uk (Redshaw C.) ORCID

Xiao Xin: 0000-0001-6432-2875; Carl Redshaw: 0000-0002-2090-1688

Notes

AUTHOR INFORMATION

The authors declare no competing financial interest.

References

(1) Hilderbrand, S. A.; Weissleder, R. Chem. Commun. 2007, 2747-2749.

(2) Briggs, M. S.; Dougal Burns, D.; Cooper, M. E.; Gregory, S. J. Chem. Commun. 2000, 2323-2324.

(3) Zhang, S.; Fan, J. L.; Li, Z. Y.; Hao, N. J.; Cao, J. F.; Wu, T.; Wang, J. Y.; Peng, X. J. J. Mat. Chem. B. 2014, 2, 2688-2693.

(4) Ornelas, C.; Lodescar, R.; Durandin, A.; Canary, J. W.; Pennell, R.; Liebes, L. F.; Weck, M. Chem. Eur. J. 2011, 17, 3619-3629.

(5) Puyol, M.; Encinas, C.; Rivera, L.; Miltsov, S.; Alonso, J. Sens Actuators B Chem. 2007, 122, 53-59.

(6) Jędrzejewska, B.; Kabatc, J.; Pietrzak, M.; Pąezkowski, J. Dyes and Pigments. 2003, 58, 47-58.

(7) Wu, D.; Chen, L. Y.; Lee, W.; Ko, G.; Yin, J.; Yoon, J. Coord. Chem. Rev. 2018, 354, 74-97. 
(8) Liu, M.; Kan, J. L.; Yao, Y. Q.; Zhang, Y. Q.; Bian, B.; Tao, Z.; Zhu, Q. J.; Xiao, X. . Sens Actuators B Chem. 2019, 283, 290-297.

(9) Xu, W. T.; Kan, J. L.; Yang, B.; Prior, T. J.; Bian, B.; Xiao, X.; Tao, Z.; Redshaw, C. Chem. Asian J. 2019, 14, 235-242.

(10) Ding, Y. N.; Yang, B. C.; Liu, H.; Liu, Z. X.; Zhang, X.; Zheng, X. W.; Liu, Q. Y. Sens Actuators B Chem. 2018, 259, 775-783.

(11) Wang, X. X.; Chen, K.; Shen, F. F.; Hua, Z. Y.; Qiu, S. C.; Zhang, Y. Q.; Cong, H.; Liu, Q. Y.; Tao, Z.; Xiao, X. Chem. Eur. J. 2017, 23, 16953-16956.

(12) Gao, Z. Z.; Kan, J. L.; Tao, Z.; Bian, B.; Xiao, X. 2018. New J. Chem. 2018, 42, 15420-15426.

(13) Meng, T. H.; Zhou, Y.; Gao, Z. Z.; Liu, Q. Y.; Tao, Z.; Xiao, X. J. Incl. Phenom. Macro. 2018, 90, 357-363.

(14) Wang, R. B.; MacGillivray, B. C.; Macartney, D. H. Dalton Trans. 2009, 3584-3589.

(15) McInnes, F. J.; Anthony, N. G.; Kennedy, A. R.; Wheate, N. J. Org. Biomol. Chem. 2010, 8, 765-773.

(16) Shetty, D.; Khedhar, J. K.; Park, K. M.; Kim, K. Chem. Soc. Rev. 2015, 44, 87478761.

(17) Barrow, S. J.; Kasera, S.; Rowland, M. J.; del barrio, J.; Scherman, O. A. Chem. Rev. 2015, 115, 12320-12406.

(18) Bhasikuttan, A. C.; Mohanty, J.; Nau, W. M.; Pal, H. Angew Chem. Int. Ed. 2007, 46, 4120-4122.

(19) Gaddle, S.; Batchelor, E. K.; Kaifer, A. E. Chem. Eur. J. 2009, 15, 6025-6031.

(20) Nau, W. M.; Mohanty, J. Int. J. Photoenergy. 2005, 7, 133-141.

(21) Yashchuk, V. M.; Kudrya, V. Yu.; Losytskyy, M. Yu.; Tokar, V. P.; Yarmoluk, S. M.; Dmytruk, I. M.; Prokopets, V. M.; Kovalska, V. B.; Balanda, A. O.; 
Kryvorotenko, D. V.; Ogul'chansky, T. Yu. Proc. of SPIE. 2007, 6796, 67960M1M14.

(22) Ramaiah, D.; Eckert, I.; Arun, K. T.; Weidenfeller, L.; Epe, B.; Photochemistry and Photobiology. 2004, 79, 99-104.

(23) Woods, J. A.; Traynor, N. J.; Brancaleon, L.; Moseley, H. Photochemistry and Photobiology. 2004, 79, 105-113.

(24) Dee, D.; Baur, M. E. J. Chem. Phys. 1974, 60, 541-560.

(25) Huang, Y. X.; Fu, Z.; Xue, S. F.; Zhu, Q. J.; Wei, G. Supramol. Chem. 2013, 25, 166-172.

(26) Day, A.; Arnold, A. P.; Blanch, R. J.; Snushall, B. J. Org. Chem. 2011, 66, 80948100.

(27) Kim, J.; Jung, I. S.; Kim, S. Y.; Lee, E.; Kang, J. K.; Sakamoto, S.; Yamaguchi, K.; Kim, K. J. Am. Chem. Soc. 2000, 122, 540-541.

(28) Kovalska, V. B.; Kryvorotenko, D. V.; Balanda, A. O.; Losytskyy, M. Yu.; Tokar, V. P.; Yarmoluk, S. M. Dyes and Pigments. 2005, 67, 47-54. 


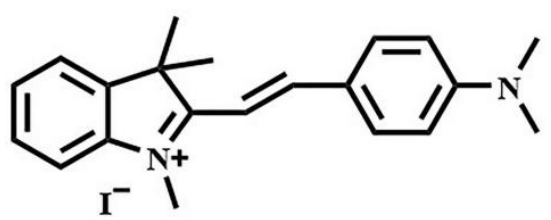

$\mathbf{H}$
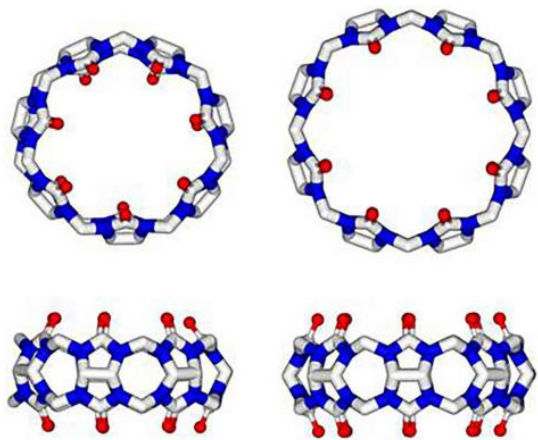

Q[7]

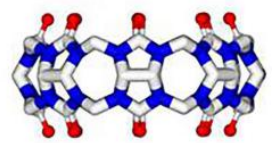

Q[8]

Scheme 1. The cucubit[n]urils Q[7] and Q[8] and the guest $H$.<smiles>CCc1cccc2cccc(CC)c12</smiles>

A<smiles></smiles>

B

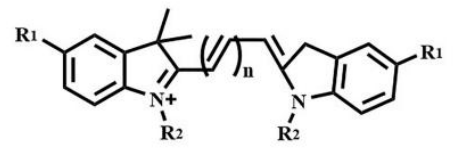

C $\mathrm{R} 1=\mathrm{H}, \mathrm{R}_{2}=\left(\mathrm{CH}_{2}\right) 4 \mathrm{SO}^{3}{ }^{-} \mathrm{n}^{-1}$

D $\mathrm{R} 1=\mathrm{H}, \mathrm{R}_{2}=\left(\mathrm{CH}_{2}\right)_{4} \mathrm{SO}^{3}{ }^{n} \mathrm{n}=2$

E $\quad \mathrm{R}_{1}=\mathrm{SO}^{3}, \mathrm{R} 2=\mathrm{Et} \mathrm{n}=\mathbf{2}$<smiles>CCN1/C(=C/C=C2\CCC(/C=C/c3sc4ccc(Cl)cc4[n+]3CC)=C2N(c2ccccc2)c2ccccc2)Sc2ccc(Cl)cc21</smiles>

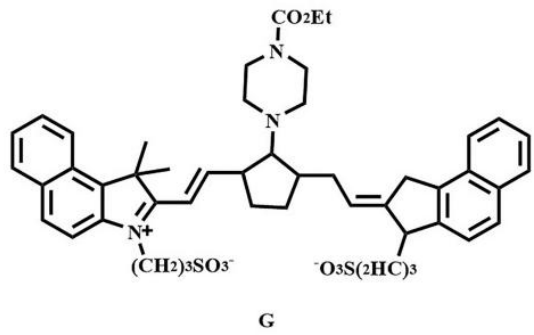

Scheme 2. Guests A and B used by Kaifer et al.(5), Guest C - G used by Nau and Mohanty.(6)

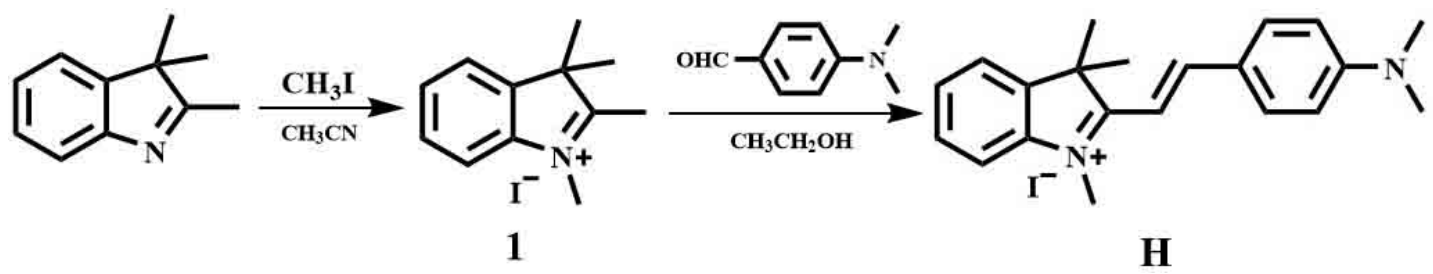

Scheme 3. Synthesis of H. 


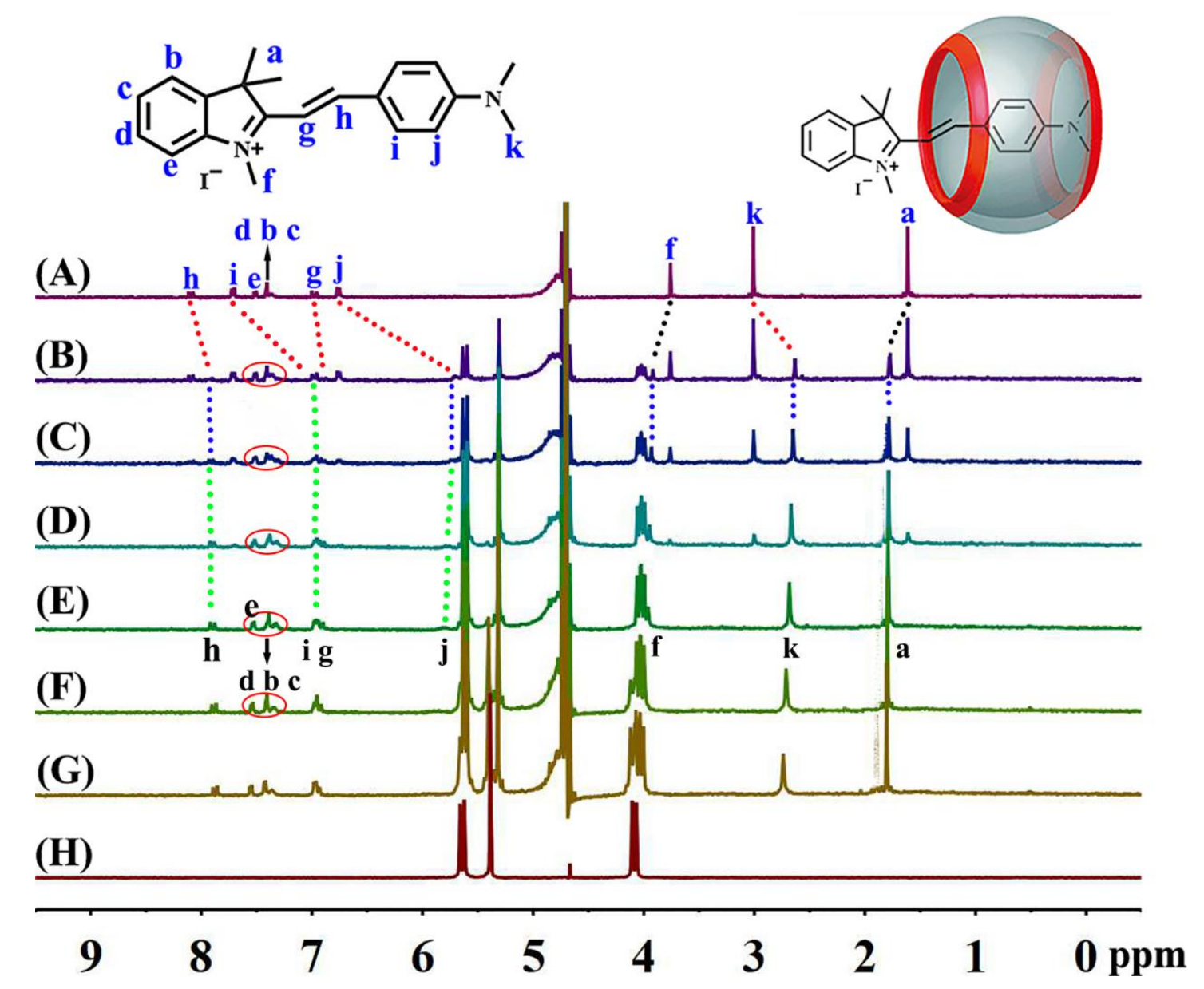

Figure 1. Interaction of $\mathrm{H}$ and Q[7] $\left(20^{\circ} \mathrm{C}\right):{ }^{1} \mathrm{H}$ NMR spectra $\left(400 \mathrm{MHz}, \mathrm{D}_{2} \mathrm{O}\right)$ of $\mathrm{H}(\mathrm{ca}$. $0.5 \mathrm{mM}$ ) in the absence (A), 0.33 equiv.(B), 0.55 equiv. Q[7] (C), 0.80 equiv.(D), 1.05 equiv. Q[7] (E), 1.43 equiv.(F), 2.07 equiv.(G) and neat of Q[7] (H). 
(A)

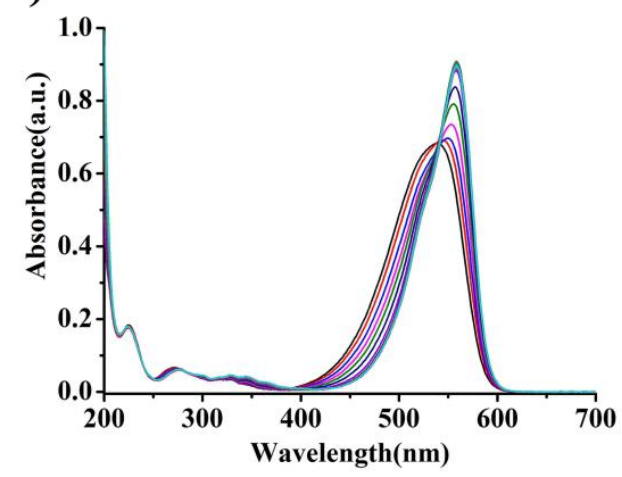

(C)

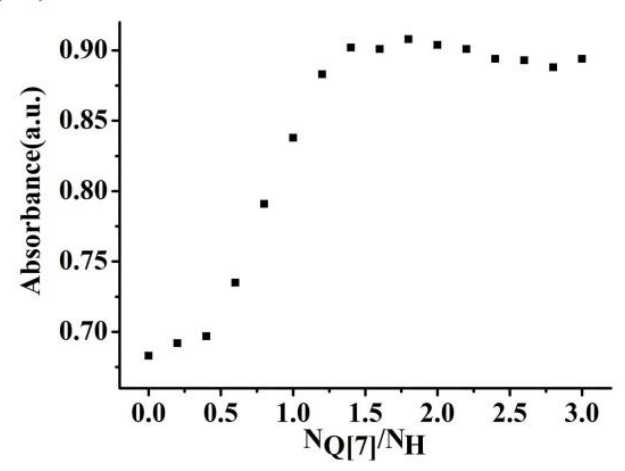

(B)

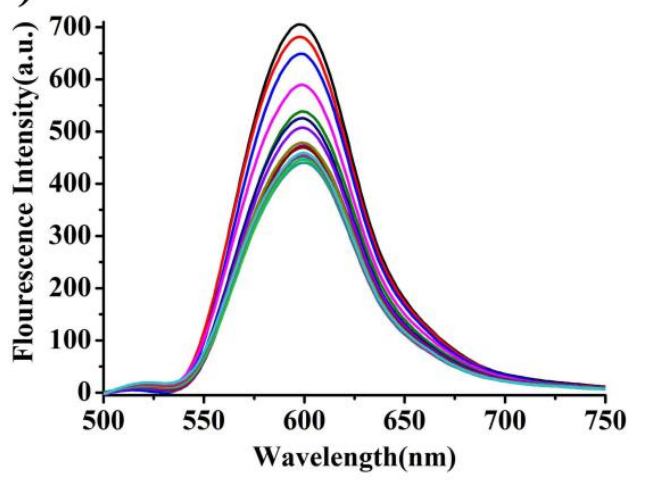

(D)

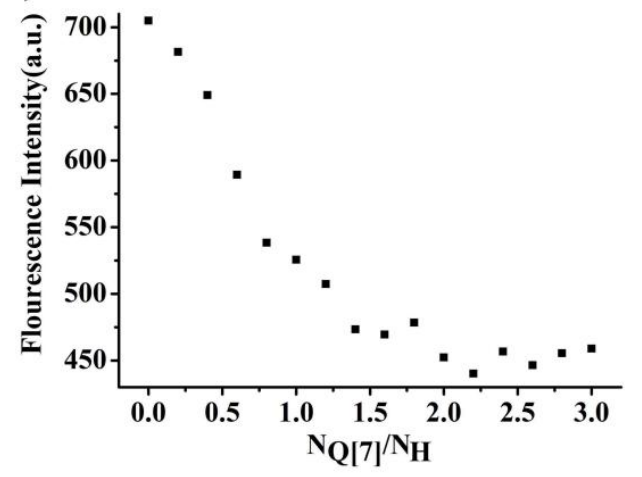

Figure 2. (Colour online) (A) Electronic absorption and (C) fluorescence spectra of $\mathrm{H}$ $\left(1 \times 10^{-5} \mathrm{~mol} \mathrm{~L}^{-1}\right)$ upon addition of increasing amounts $(0,0.2,0.4 \cdots \cdots \cdot 2.6,2.8,3.0$ equiv.) of Q[7], the concentrations and absorbance vs. $\mathrm{N}_{\mathrm{Q}[7]} / \mathrm{N}_{\mathrm{H}}$ plots (B), and the concentrations and emission vs. $\mathrm{N}_{\mathrm{Q}[7]} / \mathrm{N}_{\mathrm{H}}$ plots (D). 

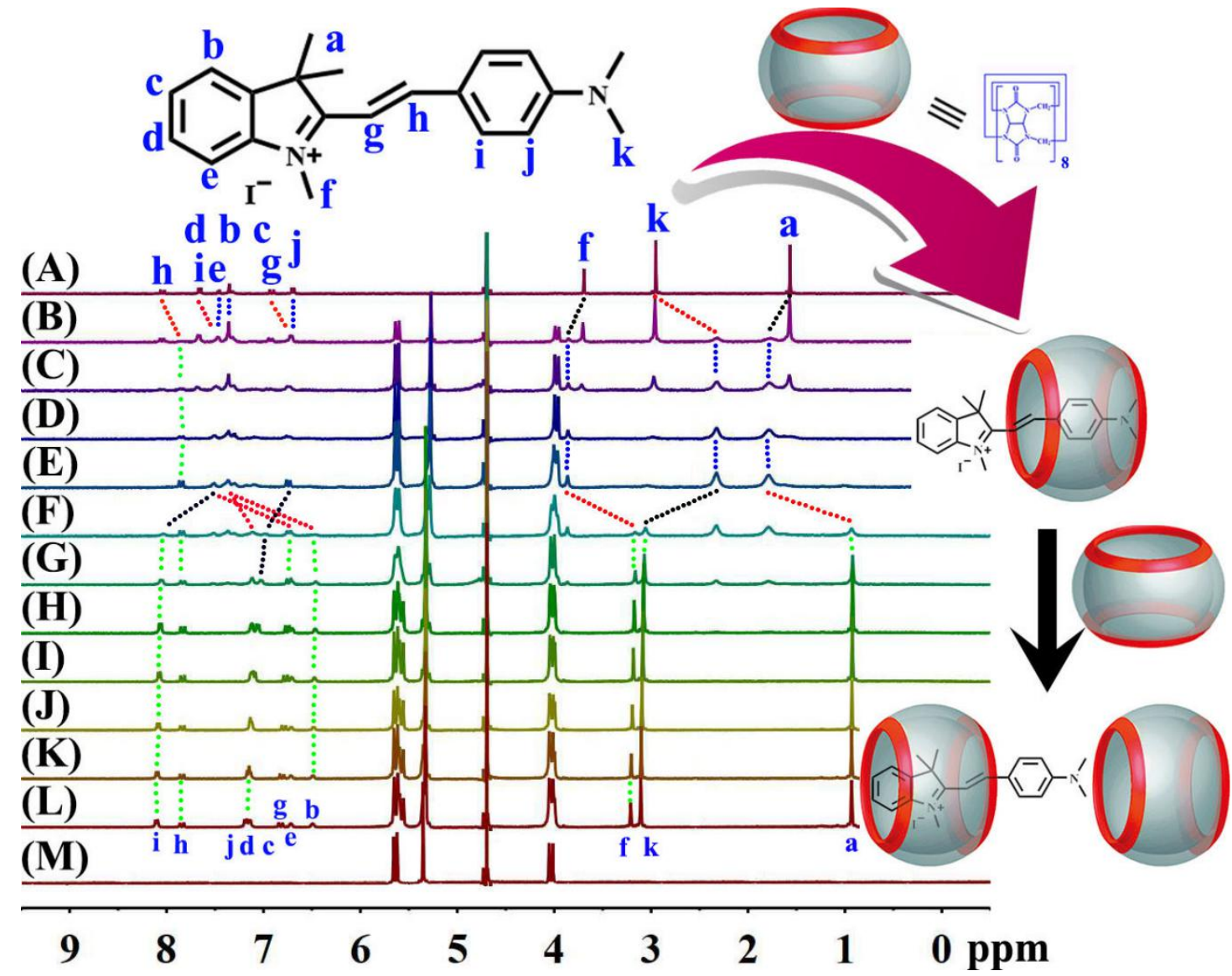

Figure 3. Interaction of $\mathrm{H}$ and Q[8] $\left(20^{\circ} \mathrm{C}\right):{ }^{1} \mathrm{H}$ NMR spectra $\left(400 \mathrm{MHz}, \mathrm{D}_{2} \mathrm{O}\right)$ of $\mathrm{H}(\mathrm{ca}$. $0.5 \mathrm{mM}$ ) in the absence (A), 0.30 equiv.(B), 0.61 equiv.(C), 0.84 equiv.(D), 1.02 equiv.(E), 1.18 equiv.(F), 1.30 equiv.(G), 1.44 equiv.(H), 1.54 equiv.(I), 1.65 equiv.(J), 1.72 equiv.(K), 1.93 equiv.(L) and neat (M) of Q[8]. 
(A)

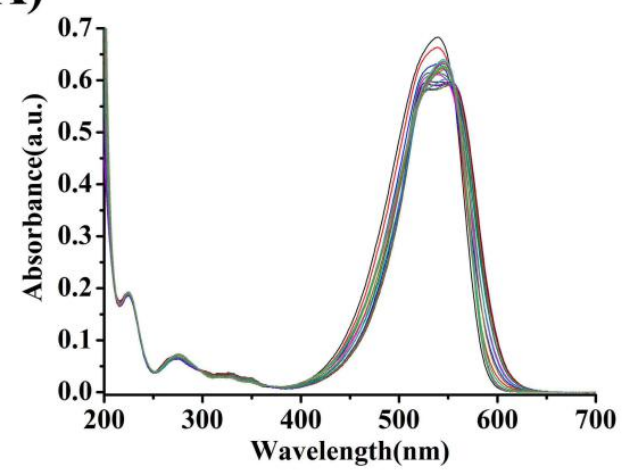

(C)

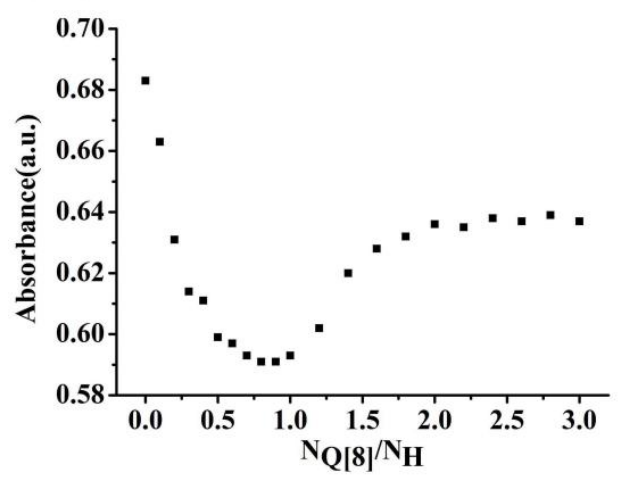

(B)

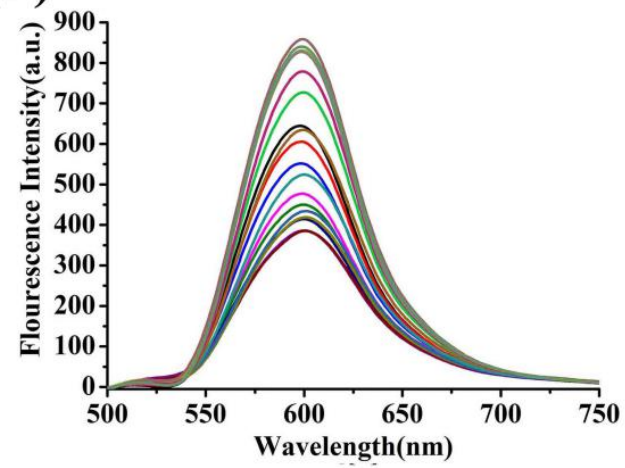

(D)

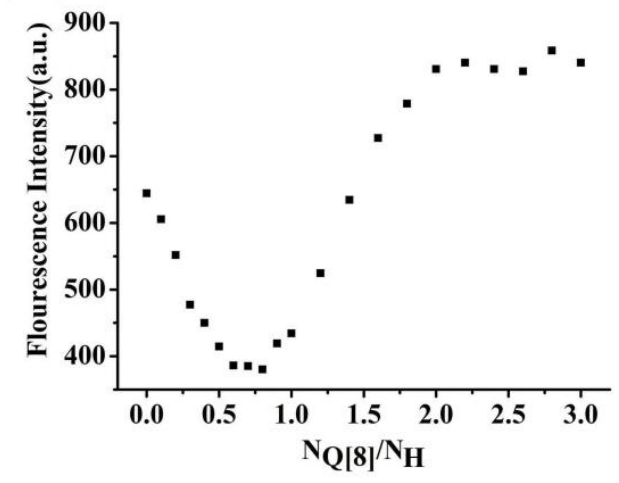

Figure 4. (Colour online) (A) Electronic absorption and (C) fluorescence spectra of H (1 $\left.\times 10^{-5} \mathrm{~mol} \mathrm{~L}^{-1}\right)$ upon addition of increasing amounts $(0,0.1,0.2 \cdots \cdots 1,1.2,1.4 \cdots \cdots 3.0$ equiv.) of Q[8], the concentrations and absorbance vs. $\mathrm{N}_{\mathrm{Q}[8]} / \mathrm{N}_{\mathrm{H}}$ plots (B), and the concentrations and emission vs. $\mathrm{N}_{\mathrm{Q}[8]} / \mathrm{N}_{\mathrm{H}}$ plots (D).
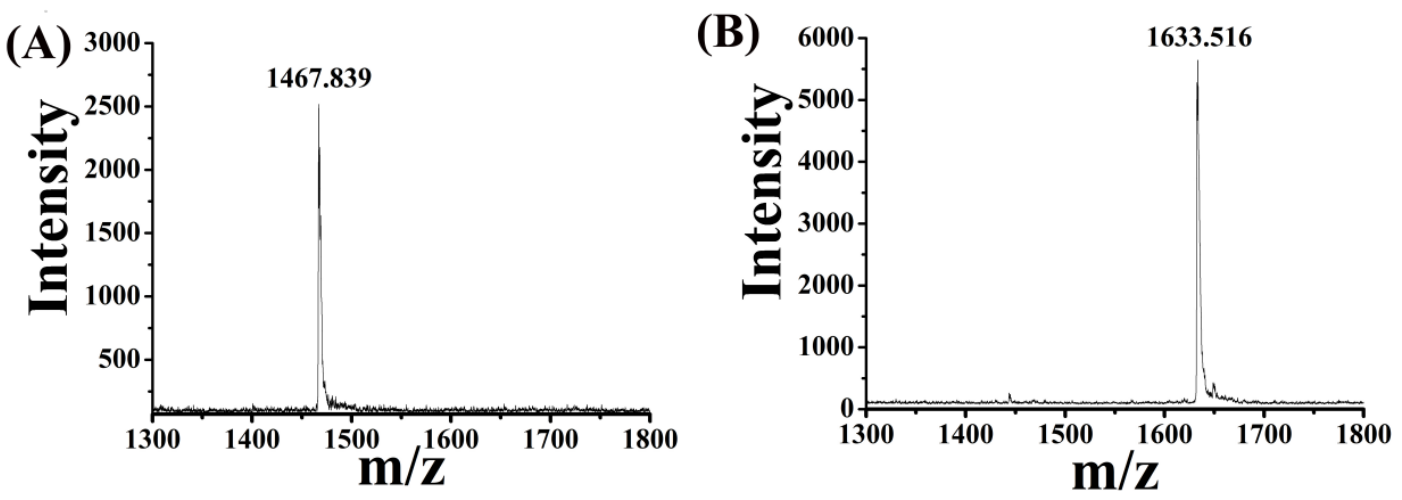

Figure 5. MALDI-TOF mass spectrometry of Q[7]@H (A) and Q[8]@H (B). 


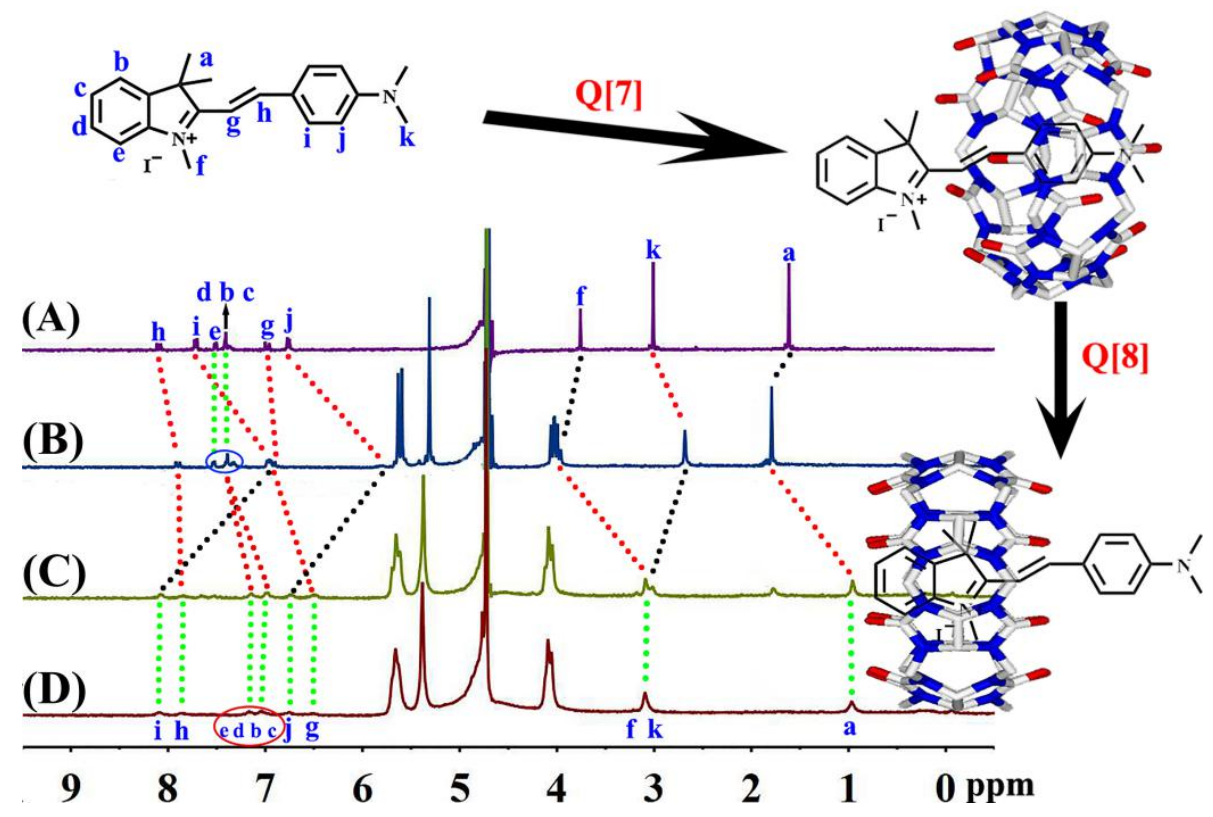

Figure 6. Interaction of $\mathrm{H}, \mathrm{Q}[7]$ and $\mathrm{Q}[8]\left(20{ }^{\circ} \mathrm{C}\right):{ }^{1} \mathrm{H}$ NMR spectra $\left(400 \mathrm{MHz}, \mathrm{D}_{2} \mathrm{O}\right)$ of $\mathrm{H}$ (ca. $0.5 \mathrm{mM}$ ) (A), in the presence of 1.02 equiv. of Q[7] (B), in the presence of 0.87 equiv. of Q[8] (C), and in the presence of 1.80 equiv. of $Q[8]$ (D).

(A)

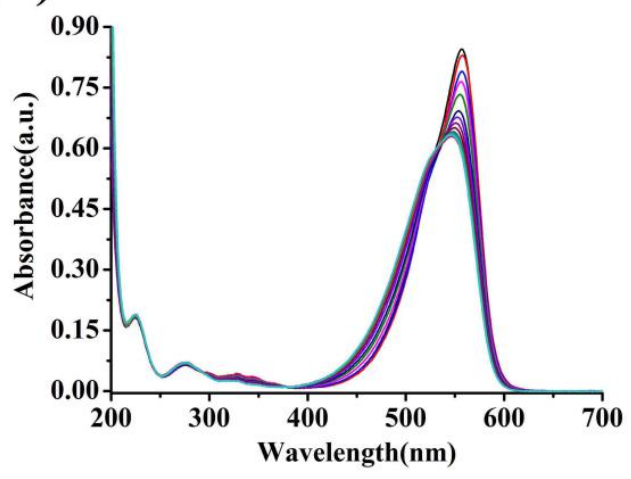

(C)

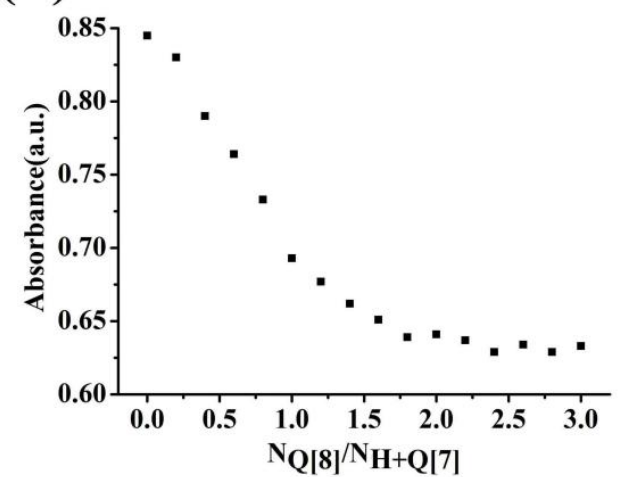

(B)

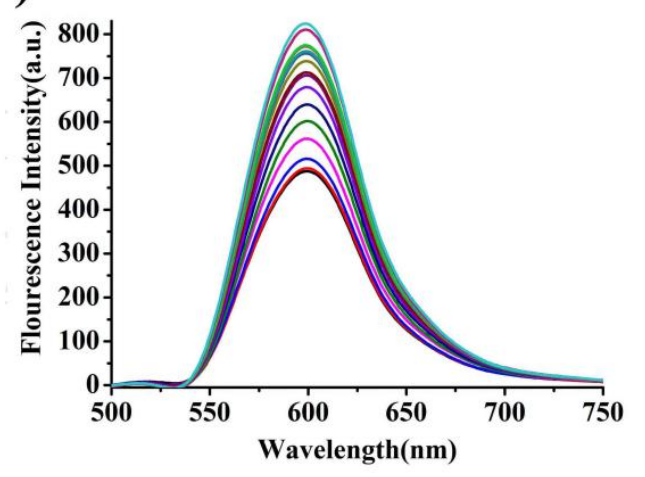

(D)

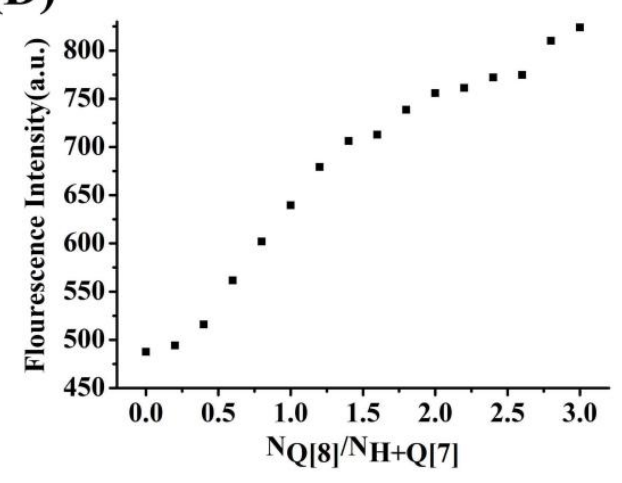


Figure 7. (Colour online) (A) Electronic absorption and (B) fluorescence spectrometry of $\mathrm{H} / \mathrm{Q}[7]\left(1: 1,1 \times 10^{-5} \mathrm{~mol} \mathrm{~L}^{-1}\right)$ upon addition of increasing amounts $(0,0.2$, $0.4 \cdots \cdots 3.0$ equiv.) of $\mathrm{Q}[8]$; (C) the concentrations and absorbance vs. $\mathrm{N}_{\mathrm{Q}[8]} / \mathrm{N}_{\mathrm{H} / \mathrm{Q}[7]}$ plots; (D) the concentrations and fluorescence emission vs. $\mathrm{N}_{\mathrm{Q}[8]} / \mathrm{N}_{\mathrm{H} / \mathrm{Q}[7]}$ plots.

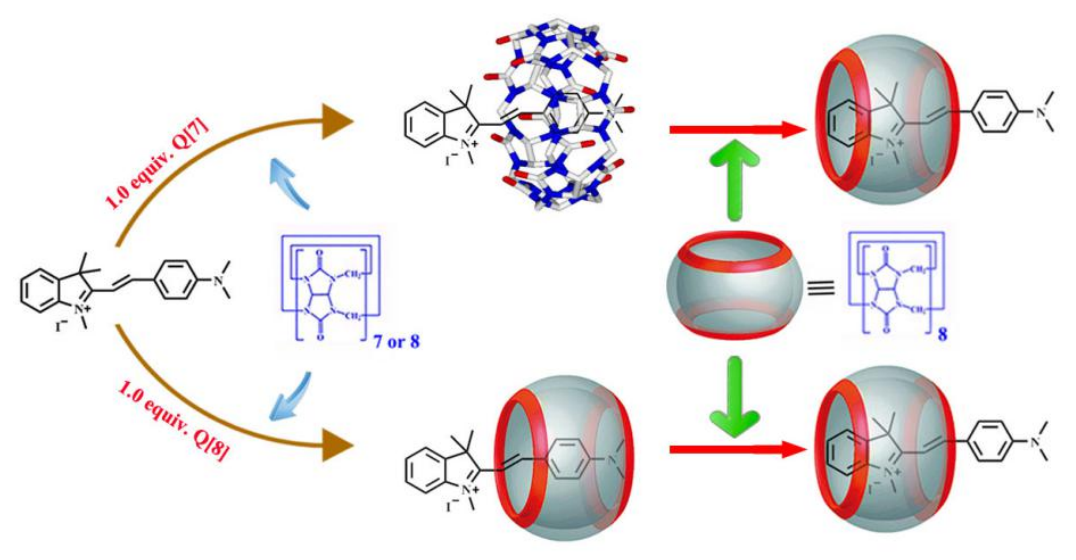

The interaction between the hemicyanine shown and the cucubit $[n]$ uril $(n=7,8)$ has been studied. Changes in the size of the $\mathrm{Q}[n]$ cavity result in differing binding behaviour.The affinity for different parts of the guest changes depending on the amount of Q[8] present, whereas for variation in the amounts of Q[7] no changes were observed. 